\title{
LDB: respeito à liberdade E apreço à tolerância
}

Toni ReIs*

RESUMO: Este artigo aborda dois princípios da LDB, respeito à liberdade e apreço à tolerância, sobretudo em relação à promoção da igualdade entre gêneros e ao respeito à diversidade sexual. Se, nas décadas de 1990 e 2000 houve grandes avanços na legislação e nas políticas públicas nestas áreas, a década de 2010 vem sendo caracterizada por afrontas violentas contra eles por setores ultraconservadores. Concluiu-se que os marcos normativos da educação brasileira dão respaldo para enfrentá-las e perseverar destemidos nos esforços de superação das desigualdades na educação.

Palavras-chave: Educação. Tolerância. Liberdade. Reacionarismo.

\section{The legal guidelines and bases for education (LDB)}

Respect for freedom and an appreciation for tolerance

\begin{abstract}
This article deals with two principles of the legal guidelines on education (LDB), respect for freedom and an appreciation for tolerance, especially in relation to the promotion of equality between the sexes and with respect to sexual diversity. If, during the 1990 's and the first decade of the 21st century, there were great advances with legislation and public policy in this area, the years from 2010 are being characterized by violent affronts between them by groups of ultraconservatives. It concludes that the normative marks of Brazilian education has fought back in order to face and persevere fearlessly in its efforts to overcome inequalities in education.
\end{abstract}

Key words: Education. Tolerance. Freedom. Reactionary.

* Doutor em Educação. Secretário de Educação da ABGLT - Associação Brasileira de Lésbicas, Gays, Bissexuais, Travestis e Transexuais, membro titular do Fórum Nacional de Educação (FNE) como representante do Movimento da Diversidade, Diretor Executivo do Grupo Dignidade e do Instituto Brasileiro de Diversidade Sexual. Curitiba/PR - Brasil. E-mail: <tonireisctba@gmail.com>. 


\section{LDB: respeto por la libertad}

$Y$ aprecio por la tolerancia

RESUMEN: Este artículo trata de dos principios de la LDB, el respeto por la libertad y el aprecio por la tolerancia, especialmente en relación con la promoción de la igualdad entre géneros y el respeto por la diversidad sexual. Si, en las décadas de 1990 y 2000, hubo grandes avances en las leyes y en las políticas públicas sobre estas cuestiones, la década de 2010 se caracteriza por agresiones violentas contra ellos por parte de sectores ultraconservadores. Se concluye que los marcos reguladores de la educación brasileña dan respaldo para enfrentarlas y perseverar sin miedo en los esfuerzos de superación de las desigualdades en la educación.

Palabras clave: Educación. Tolerancia. Libertad. Tendencia reaccionaria.

\section{LDB: Le respect de la liberté \\ Et le goût de la tolérance}

RÉSUMÉ: Cet article traite de deux des principes de la LDB, le respect de la liberté et le goût de la tolérance, en particulier en ce qui concerne la promotion de l'égalité entre les sexes et le respect de la diversité sexuelle. Si, dans les décennies 1990 et 2000, il y a eu de grands progrés dans la législation et dans les politiques publiques dans ces domaines; la décennie 2010 se caractérise par de violentes atteintes contre ceux-ci par les secteurs ultraconservateurs. On peut ainsi conclure que les cadres normatifs de l'éducation brésiliennes sont un soutien pour lutter contre ces atteintes et pour perséver, inébranlables, dans les effort pour surmonter les inégalités dans l'éducation.

Mots-clés: Education. Tolérance. Liberté. Réactionnisme. 


\section{Introdução}

Lei de Diretrizes e Bases da Educação Nacional, de 1996, trouxe entre seus
vários princípios o do "respeito à liberdade e apreço à tolerância" (BRASIL,
1996). Passados vinte anos, até que ponto este ideal se tornou mais próximo da realidade na educação e na sociedade brasileiras para todos os segmentos da população?

Em relação às mulheres, às pessoas LGBT (lésbicas, gays, bissexuais, travestis e transexuais), às pessoas negras e às pessoas de regiões menos favorecidas, os acalorados debates sobre o Plano Nacional de Educação 2014-2024 e os respectivos Planos Estaduais e Municipais de Educação trouxeram à tona um grau assustador de intolerância e desrespeito à liberdade alheia por parte de determinados setores reacionários, conservadores e fundamentalistas.

Os Planos de Educação tiveram como uma de suas fontes norteadoras as deliberações da Conferência Nacional de Educação Básica (BRASIL, 2008) e da Conferência Nacional de Educação (Conae) (BRASIL, 2010a). A Conae de 2014 foi realizada em novembro daquele ano (BRASIL, 2014a), após a aprovação da Lei nํ⒔005 / Plano Nacional de Educação em 25 de junho do mesmo ano (BRASIL, 2014b), embora suas etapas municipais e estaduais preparatórias anteriores possam ter contribuído para as discussões sobre o Plano Nacional. Também contribuíram para este processo diversas Conferências Sociais Temáticas, como as Conferências Nacionais de Políticas para as Mulheres (BRASIL 2004a; 2013a; 2013b), as Conferências Nacionais de Promoção da Igualdade Racial (BRASIL, 2005; 2009a; 2013c) e as Conferências Nacionais LGBT (BRASIL, 2009b; 2011), entre outras, bem como o próprio Programa Nacional de Direitos Humanos III (BRASIL, 2010b). Ou seja, houve ampla discussão em todos os níveis (municipal, estadual e nacional), com as mais diversas representações, para que as deliberações aprovadas nas conferências nacionais refletissem adequadamente as necessidades de cada uma das áreas no que diz respeito às políticas públicas, inclusive as políticas públicas de educação.

A Conferência Nacional de Educação Básica aprovou entre as deliberações no Eixo Temático IV (Inclusão e Diversidade na Educação), a reivindicação de que as políticas de educação garantissem

[...] a todos (quilombolas, negros, indígenas, pessoas com necessidades educacionais especiais, gays, lésbicas, bissexuais, travestis, transexuais e transgêneros (GLBTTT), pessoas privadas de liberdade, mulheres, jovens, adultos e idosos), o acesso e a permanência com sucesso à educação de qualidade, tudo articulado às políticas sociais. (BRASIL, 2008, p. 68).

Da mesma forma, as deliberações da Conferência Nacional de Educação de 2010, fazem repetidas referências à superação das desigualdades regionais e, no Eixo VI - Justiça Social, Educação e Trabalho: Inclusão, Diversidade e Igualdade - apresentam diversas demandas voltadas para a eliminação de desigualdades, preconceito e 
discriminação na educação no que diz respeito a gênero e diversidade sexual e questões étnico-raciais. (BRASIL, 2010a).

Assim, a versão do projeto de lei do Plano Nacional de Educação, apresentada em dezembro de 2010 e aprovada em 2012 pela Câmara dos Deputados antes de ser encaminhada para apreciação pelo Senado, continha entre suas diretrizes a "superação das desigualdades educacionais, com ênfase na promoção da igualdade racial, regional, de gênero e de orientação sexual"' (BRASIL, 2012a), refletindo assim as democraticamente construídas deliberações das Conferências Sociais.

Além de trazidas por um processo (as Conferências) com representação dos sujeitos (meninas e mulheres, pessoas negras, pessoas LGBT e pessoas afetadas pelas desigualdades regionais), estas deliberações também se encontram respaldadas nos resultados de pesquisas científicas e em dados oficiais.

Pesquisa que contou com a própria participação do Ministério da Educação e que ouviu uma amostra nacional de 18,5 mil estudantes, pais e mães, diretores, professores e funcionários revelou os seguintes percentuais de respondentes com algum nível de preconceito com relação aos seguintes assuntos: étnico-racial, 94,2\%; gênero, 93,5\%; orientação sexual, 87,35; territorial, 75,9\%. Os respondentes também afirmaram ter conhecimento de práticas discriminatórias sofridas por estudantes por serem negros $(19,0 \%)$; homossexuais $(17,4 \%)$; mulheres $(10,9 \%)$; por questões territoriais $(8,9 \%)$. (MAZZON, 2009, grifos nossos).

O Mapa da Violência de 2012 informa que, entre os anos 2002 e 2010, foram assassinadas 272.422 pessoas negras no País, representando 65\% do total de todos os homicídios no período. Ainda, 159.543 (59\%) de todas as pessoas negras assassinadas eram jovens (WAISELFISZ, 2012).

Em outra publicação, o mesmo autor revela que entre os anos 1980 e 2013 foram assassinadas 106.093 mulheres no Brasil, aumentando gradativamente anualmente de 3.851 no ano de 2001, para 4.762 no ano de 2013. Ainda, no ano de 2013, 60\% (2.875) das vítimas eram negras e $27 \%$ dos assassinatos ocorreram no próprio domicílio delas. (WAISELFISZ, 2015).

A assim chamada "cultura do estupro" também traz dados assustadores sobre a violência de gênero no Brasil. Segundo o Anuário Brasileiro de Segurança Pública 2015, houve registro de 47.646 estupros no país em 2014 (uma redução de 6,7\% em relação ao ano de 2013). No entanto, a mesma fonte considera que 35\% dos crimes sexuais não são notificados, de modo que o número de estupros pode ser muito maior. (FÓRUM, 2015).

Em relação à população LGBT, segundo a Secretaria de Direitos Humanos do Governo Federal, “em 2012, foram registradas pelo poder público 3.084 denúncias de 9.982 violações [de direitos humanos] relacionadas à população LGBT, envolvendo 4.851 vítimas e 4.784 suspeitos." (BRASIL, 2013d, p. 18). A mesma fonte registrou 310 homicídios de pessoas LGBT no Brasil no mesmo ano por motivos LGBTfóbicos. (BRASIL, 
2013d). A Secretaria de Direitos Humanos publicou em 2016 a seguinte descrição das violações de direitos humanos e dos assassinatos de pessoas LGBT:

Dados do Disque 100 indicam que entre 2011 e 2015 mais de 16 mil violações contra a população LGBT foram denunciadas, estando entre as mais frequentes as violências física e psicológica e a discriminação. Para compreender também a especificidade e o grau da violência homofóbica, faz-se imprescindível conhecer os tipos bárbaros de agressões infringidas contra a população LGBT. De acordo com a pesquisa hemerográfica em 2013,22,4\% das vítimas [dos homicídios] sofreram facadas; $21,9 \%$ foram alvejados a tiros; $8,6 \%$ foram espancados; $6,2 \%$ foram estrangulados; $5,2 \%$ foram apedrejados; $4,4 \%$ sofreram pauladas; $2,6 \%$ foram asfixiados; 1,6 foram carbonizados e $0,5 \%$ foram afogados. Algumas vítimas sofreram mais de um tipo desses ataques. Esses dados apontam de modo eloquente para a gravidade e o ódio com que os crimes de caráter homofóbico costumam ser cometidos no Brasil. (BRASIL, 2016a, p. 21).

\section{Oposição virulenta}

Apesar dos nítidos e graves problemas em relação às diversas formas de violência por motivos de gênero, etnia e raça, orientação sexual e identidade de gênero, bem como procedência regional, quando o projeto de lei do Plano Nacional de Educação (PNE) chegou ao Senado, esbarrou contra um virulento movimento de oposição contra a menção específica dessas formas de injustiça nas diretrizes do Plano.

Em especial, esse movimento contrário ganhou força e promoveu alianças entre setores reacionários em nome do combate à "ideologia de gênero". Segundo o argentino Jorge Scala, um dos seus mais articulados opositores, "ideologia de gênero" significa que

[...] o sexo seria o aspecto biológico do ser humano, e o gênero seria a construção social ou cultural do sexo. Ou seja, que cada um seria absolutamente livre, sem condicionamento algum, nem sequer o biológico, para determinar seu próprio gênero, dando-lhe o conteúdo que quiser e mudando de gênero quantas vezes quiser.

Agora, se isso fosse verdade, não haveria diferenças entre homem e mulher - exceto as biológicas; qualquer tipo de união entre os sexos seria social e moralmente boas, e todas seriam matrimônio; cada tipo de matrimônio levaria a um novo tipo de família; o aborto seria um direito humano inalienável da mulher, já que somente ela é que fica grávida; etc. Tudo isso é tão absurdo, que só pode ser imposto com uma espécie de "lavagem cerebral" global (...) O gênero destrói a estrutura antropológica íntima do ser humano... (SCALA, 2012)

O uso do termo gênero na definição de Scala é uma crítica ao debate sobre o gênero visualizado como um construto cultural. No entanto, desqualifica décadas de discussões, consensos, acordos internacionais e políticas nacionais sobre a necessidade de promover a igualdade entre os gêneros, entre masculino e feminino, em um mundo caracterizado em sua grande maioria pela inferiorização das meninas e mulheres perante os meninos 
e os homens. A diretriz da proposta do PNE que destacava a superação das desigualdades de gênero dizia respeito a este último objetivo e não à desconstrução do masculino e do feminino. Além disso, Scala atrela ao gênero, conforme definido por ele, vários tópicos polêmicos que suscitam a ira dos reacionários, como o aborto e o matrimônio fora do padrão da família tradicional, entendendo-se implicitamente também a união entre pessoas do mesmo sexo.

A falácia da "ideologia de gênero" disseminada por Scala e por outros ganhou força acrítica no debate sobre o PNE, transformando-se, para alguns, em uma verdade absoluta e inquebrantável, sobretudo entre os setores religiosos conservadores, quando não fundamentalistas, e entre os que se autodenominam os defensores dos "valores tradicionais", inclusive no meio político e legislativo.

Assim, a versão do projeto de lei do PNE que retornou do Senado para a Câmara dos Deputados - e que foi aprovada e sancionada - ficou desprovida não somente da parte da diretriz que visava à da promoção da igualdade de gênero e de orientação sexual, como também perdeu-se nessa batalha o objetivo de promover a igualdade racial e regional. O texto da versão final da referida diretriz do PNE ficou com uma redação genérica: "superação das desigualdades educacionais, com ênfase na promoção da cidadania e na erradicação de todas as formas de discriminação". (BRASIL, 2014b).

\section{Campanha de intimidação}

Mas o debate não parou por aí, pelo contrário, se intensificou e se radicalizou no decorrer do processo subsequente da elaboração e aprovação dos planos estaduais e municipais de educação. Tanto que, além de extirpar a palavra gênero dos planos, houve municípios que aprovaram planos de educação que vedam a "adoção de políticas de ensino que tendam a aplicar a ideologia de gênero, o termo 'gênero' ou 'orientação sexual'." (PARANAGUÁ, 2015). Ademais, segundo levantamento da iniciativa "De Olho nos Planos de Educação", das vinte e cinco Unidades da Federação que aprovaram planos de educação até 12 de julho de 2016, doze excluíram a palavra gênero (DE OLHO NOS PLANOS, 2016).

Além disso, difundiu-se uma campanha de intimidação aos/às profissionais de educação, por meio da entrega em diversas escolas no Brasil afora de notificações extrajudiciais com o seguinte conteúdo direcionadas aos "professores desta escola (...) para que, em caráter peremptório, se abstenham de apresentar, ministrar, ensinar, ou por outra forma, informar qualquer dos temas relativos a matéria descrita no preâmbulo desta ao meu filho", sob pena de processo. Os temas descritos no preâmbulo incluem "ideologia de gênero e outras propostas a serem objeto de apresentação para as crianças nas 
escolas, especificamente, sobre temas relacionados com comportamentos sexuais especiais (homossexualidade, bissexualidade, transsexualidade (sic), etc.)...". (PUGGINA, 2015).

As tentativas de censurar a liberdade de cátedra dos/das profissionais de educação não se restringiram às descritas acima. Desde meados dos anos 2000, vem se organizando um movimento chamado Escola Sem Partido, supostamente contra a doutrinação nas escolas, ou seja, a utilização do espaço escolar pelo/pela professor/a para difundir suas próprias convicções junto ao seu público cativo: os/as estudantes. O movimento encontrou um aliado no senador Magno Malta (PR/ES), que propôs o Projeto de Lei do Senado nº 193, de 2016, que visa à "inclusão entre as diretrizes e bases da educação nacional, de que trata a Lei no 9.394, de 20 de dezembro de 1996, do 'Programa Escola sem Partido'” (BRASIL, 2016b). A justificativa do Projeto de Lei afirma que

É fato notório que professores e autores de materiais didáticos vêm se utilizando de suas aulas e de suas obras para tentar obter a adesão dos estudantes a determinadas correntes políticas e ideológicas para fazer com que eles adotem padrões de julgamento e de conduta moral - especialmente moral sexual - incompatíveis com os que lhes são ensinados por seus pais ou responsáveis. (BRASIL, 2016b).

A partir do trecho da justificativa acima citada, fica evidente que o propósito do Projeto de Lei, além de abarcar as pretensões do movimento Escola Sem Partido, também pretende consolidar as vedações de políticas de ensino de 'ideologia de gênero', 'gênero' ou 'orientação sexual' que surgiram em alguns Planos de Educação, conforme visto mais acima.

Importante ressaltar que, para o Ministério Público Federal,

O PLS subverte a atual ordem constitucional, por inúmeras razões: (i) confunde a educação escolar com aquela que é fornecida pelos pais e, com isso, os espaços público e privado; (ii) , impede o pluralismo de ideias e de concepções pedagógicas (art. 206, III): (iii) nega a liberdade de cátedra e a possibilidade ampla de aprendizagem (art. 206, II); (iv) contraria o princípio da laicidade do Estado, porque permite, no âmbito da escola, espaço público na concepção constitucional, a prevalência de visões morais/religiosas particulares.

Enfim, e mais grave, o PLS está na contramão dos objetivos fundamentais da República Federativa do Brasil, especialmente os de "construir uma sociedade livre, justa e solidária" e de "promover o bem de todos, sem preconceitos de origem, raça, sexo, cor, idade e quaisquer ouras formas de discriminação" (BRASIL, 2016c, p.2). 


\section{Reagindo ao retrocesso}

É encorajador perceber que, apesar das tentativas de forças reacionárias e fundamentalistas de impor suas agendas acima dos preceitos constitucionais e democráticos, existem organismos guardiões desses mesmos preceitos atentos e atuantes ao cenário atual.

O que se pode constatar nestes vinte anos da Lei de Diretrizes e Base da Educação Nacional (LDB) são etapas distintas. Na década de 1990 e de 2000, houve tentativas significativas voltadas para o alcance do princípio do respeito à liberdade e apreço à tolerância na educação em relação às populações discutidas neste artigo: pessoas negras, pessoas LGBT e meninas e mulheres. Apenas alguns exemplos incluem os Parâmetros Curriculares Nacionais: pluralidade cultural e orientação sexual (BRASIL, 1997); a Lei 10.369, de 2003, que incluiu no currículo oficial da Rede de Ensino a obrigatoriedade da temática "História e Cultura Afro-Brasileira" (BRASIL, 2003); o programa Brasil Sem Homofobia (BRASIL, 2004b); e o primeiro Plano Nacional de Políticas para as Mulheres (BRASIL, 2006).

Já a década de 2010 vem sendo caracterizada por retrocessos, a começar pela emblemática suspensão do material do projeto Escola Sem Homofobia em maio de 2011 (DILMA ROUSSEFF, 2011) e o precedente que esta ação presidencial abriu em detrimento dos esforços de promover a igualdade entre os gêneros e o respeito à diversidade sexual, inclusive na educação, a exemplo do destaque aprovado pela Câmara dos Deputados que retirou a frase "perspectivas de gênero" das atribuições do Ministério das Mulheres, em fevereiro de 2016 (DESTAQUE, 2016), ou a criação do Comitê de Gênero no âmbito do Ministério da Educação, em 9 de setembro de 2015 (BRASIL, 2015a), e sua rápida transformação no Comitê de Combate à Discriminação, já em 21 de setembro de 2015 (BRASIL 2015b).

Os/as profissionais de educação, preocupados em atuar na sala de aula para contribuir para a superação das desigualdades na educação e na própria sociedade, inclusive desigualdades de gênero e de orientação sexual, não devem se deixar intimidar por esses esforços escusos. Entre diversas outras garantias, têm todo o respaldo do direito de liberdade de cátedra, estabelecido no artigo 206 da Constituição Federal (BRASIL, 1988) e nas diretrizes da LDB (BRASIL, 1996). O artigo 3ํ das Diretrizes Nacionais para a Educação em Direitos Humanos dispõe tanto sobre a questão da diversidade quanto sobre o ensino livre da interferência religiosa, estabelecendo que a educação em direitos humanos, 
Por sua vez, o próprio Plano Nacional de Educação 2014-2024 tem entre suas diretrizes a "promoção dos princípios do respeito aos direitos humanos, à diversidade [...]". (BRASIL, 2014b), também respaldando a atuação dos/das profissionais de educação neste trabalho.

Por último, nos casos dos argumentos contra a abordagem dos temas de gênero e diversidade sexual na sala de aula baseados no preceito constitucional da liberdade de consciência e crença e da liberdade de expressão (BRASIL, 1988), deve-se lembrar que, conforme decisão do Supremo Tribunal Federal, "a garantia constitucional da liberdade de expressão não é absoluta, podendo ser afastada quando ultrapassar seus limites morais e jurídicos [...] em nome dos princípios da dignidade da pessoa humana e da igualdade jurídica." (BRASIL, 2004c).

Em suma, os princípios do respeito à liberdade e apreço à tolerância, consagrados na Lei de Diretrizes e Bases da Educação Nacional, vêm sendo fortemente ameaçados nos últimos anos por forças ultraconservadoras e intolerantes, especial mas não unicamente em relação à igualdade entre os gêneros e ao respeito à diversidade sexual. Por outro lado, os marcos normativos da educação nacional, desde a Constituição Federal, fornecem todo o alicerce necessário para enfrentar essas forças, promover a igualdade e o respeito na educação, e devem prevalecer.

Recebido em outubro de 2016 e aprovado em dezembro de 2016

\section{Referências}

BRASIL. Constituição da República Federativa do Brasil de 1988. Disponível em: <http://www. planalto.gov.br/ccivil_03/Constituicao/Constituicao.htm>. Acesso em: 08 set. 2016.

. Estabelece as diretrizes e bases da educação nacional. Diário Oficial [da] República Federativa do Brasil, Brasília, DF, 23 dez. 1996. Disponível em: <http://www.planalto.gov.br/ccivil_03/Leis/L9394. htm>. Acesso em: 11 out. 2016.

. Ministério da Educação e do Desporto. Secretaria de Educação Fundamental. Parâmetros curriculares nacionais: pluralidade cultural, orientação sexual. Brasília: MEC/SEF, 1997. Disponível em: <http://portal.mec.gov.br/seb/arquivos/pdf/livro101.pdf>. Acesso em: 09 nov. 2016.

.Lei no 10.369, de 9 de janeiro de 2003. Altera a Lei nº.394, de 20 de dezembro de 1996, que estabelece as diretrizes e bases da educação nacional, para incluir no currículo oficial da Rede de Ensino a obrigatoriedade da temática "História e Cultura Afro-Brasileira", e dá outras providências. Diário Oficial [da] República Federativa do Brasil, Brasília, DF, 10 jan. 2003. Disponível em: <https:// www.planalto.gov.br/ccivil_03/leis/2003/L10.639.htm>. Acesso em: 12 out. 2016.

. Presidência da República. Secretaria Especial de Políticas para as Mulheres. I Conferência Nacional de Políticas para as Mulheres (2004). Anais. Brasília: SPM/PR, 2004a. 
Conselho Nacional de Combate à Discriminação. Brasil Sem Homofobia: Programa de combate à violência e à discriminação contra GLTB e promoção da cidadania homossexual. Brasília: Ministério da Saúde, 2004b.

Supremo Tribunal Federal. Habeas Corpus no 82.424. Diário da Justiça, Brasília, DF, 19 mar. 2004c. Disponível em: <http://www2.stf.jus.br/portalStfInternacional/cms/verConteudo.php?sigla=port alStfJurisprudencia_pt_br\&idConteudo=185077\&modo=cms $>$. Acesso em: 12 nov. 2016.

- Secretaria Especial de Políticas de Promoção da Igualdade Racial, Conselho Nacional de Promoção da Igualdade Racial. I Conferência Nacional de Promoção da Igualdade Racial (2005). Relatório Final. Brasília: SEPPIR, 2005.

Presidência da República. Secretaria Especial de Políticas para as Mulheres. Plano Nacional de Políticas para as Mulheres. Brasília: Secretaria Especial de Políticas para as Mulheres, 2006.

Ministério da Educação. Conferência Nacional da Educação Básica (2008). Documento Final. Brasília: Presidência da República, Ministério da Educação, Secretaria Executiva, Secretaria Executiva Adjunta, Comissão Organizadora da Conferência Nacional da Educação Básica, 2008.

Presidência da República. Secretaria Especial de Políticas de Promoção da Igualdade Racial. II Conferência Nacional de Promoção da Igualdade Racial (2009). Resoluções da 2a Conapir. Brasília: SEPPIR/PR, 2009a.

Presidência da República. Secretaria Especial dos Direitos Humanos. Plano Nacional de Promoção da Cidadania e dos Direitos Humanos de LGBT. Brasília: Secretaria Especial dos Direitos Humanos, 2009b.

Comissão Organizadora Nacional da Conferência Nacional de Educação (2010). Documento

Final. Brasília: Ministério da Educação, Secretaria Executiva, 2010a.

Presidência da República. Secretaria Especial dos Direitos Humanos. Programa Nacional de Direitos Humanos (PNDH-3). Brasília: Secretaria Especial dos Direitos Humanos, 2010b.

Presidência da República. Secretaria de Direitos Humanos. Anais da II Conferência Nacional de Políticas Públicas e Direitos Humanos para LGBT. Brasília: SDH/PR, 2011.

Câmara dos Deputados. Comissão de Constituição e Justiça e de Cidadania. Redação Final.

Projeto de Lei no 8.083-B, de 2010. Aprova o Plano Nacional de Educação - PNE e dá outras providências. Brasília, DF, 16 out. 2012a. Disponível em: <http://www2.camara.leg.br/proposicoesWeb/ prop_mostrarintegra;jsessionid=7129FE0836A78035A52415DA0D4A031F.proposicoesWeb2?codteor=10 33265\&filename=Tramitacao-PL+8035/2010>. Acesso em 12 nov. 2016.

Conselho Nacional de Educação. Resolução CNE/CP 1, de 30 de maio de 2012. Estabelece Diretrizes Nacionais para a Educação em Direitos Humanos. Diário Oficial [da] República Federativa do Brasil, Brasília, DF, 31 mai. 2012b. Disponível em:< http://portal.mec.gov.br/index. php?option=com_docman\&view=download\&alias=10889-rcp001-12\&category_slug=maio-2012pdf\&Itemid=30192>. Acesso em: 18 out. 2016.

Presidência da República. Secretaria Nacional de Políticas para as Mulheres. II Conferência Nacional de Políticas para as Mulheres (2007). Anais. Brasília: SPM/PR, 2013a.

. Presidência da República. Secretaria de Políticas para as Mulheres. III Conferência Nacional de Políticas para as Mulheres (2011). Anais. Brasília: SPM/PR, $2013 b$.

Presidência da República. Secretaria de Políticas de Promoção da Igualdade Racial. III Conferência Nacional de Promoção da Igualdade Racial (2013). Resoluções da 3ª Conapir. Brasília: SEPPIR/PR, 2013c. 
Presidência da República. Secretaria de Direitos Humanos. Relatório sobre violência homofóbica no Brasil: ano de 2012. Brasília, DF: Secretaria de Direitos Humanos, 2013d. Disponível em: <http://www.sdh.gov.br/assuntos/lgbt/pdf/relatorio-violencia-homofobica-ano-2012>. Acesso em: 05 out. 2016.

. Fórum Nacional de Educação. Documento Final da Conferência Nacional de Educação 2014. Brasília: Ministério da Educação, 2014a.

. Lei no 13.005, de 25 de junho de 2014. Aprova o Plano Nacional de Educação - PNE e dá outras providências. Diário Oficial [da] República Federativa do Brasil, Brasília, DF, 26 jun. 2014b. Disponível em:<http://www.planalto.gov.br/ccivil_03/_ato2011-2014/2014/lei/113005.htm>. Acesso em: 14 nov. 2016.

Ministério da Educação. Gabinete do Ministro. Portaria no 916, de 9 de setembro de 2015. Institui Comitê de Gênero, de caráter consultivo, no âmbito do Ministério da Educação. Diário Oficial [da] República Federativa do Brasil, Brasília, DF, 10 set. 2015a. Disponível em: <http://www. editoramagister.com/legis_27020839_PORTARIA_N_916_DE_9_DE_SETEMBRO_DE_2015.aspx>. Acesso em: 24 nov. 2016.

Ministério da Educação. Gabinete do Ministro. Portaria nº 949, de 21 de setembro de 2015. Institui Comitê de Combate à Discriminação, de caráter consultivo, no âmbito do Ministério da Educação. Diário Oficial [da] República Federativa do Brasil, Brasília, DF, 22 set. 2015b. Disponível em: <http://www.lex.com.br/legis_27024038_PORTARIA_N_949_DE_21_DE_SETEMBRO_DE_2015. aspx>. Acesso em: 24 nov. 2016.

. Ministério da Justiça; Secretaria Especial de Direitos Humanos, Secretaria Nacional de Promoção dos Direitos da Criança e do Adolescente, e Secretaria Especial de Promoção dos Direitos da Pessoa com De_ciência. / Orientações para apresentação de Emendas Parlamentares ao Projeto de Lei Orçamentária Anual - PLOA, PL18/2016 CN. - Brasília: MJ, 2016a. Disponível em: <http://www.sdh. gov.br/noticias/pdf/cartilha-ploa-2017>. Acesso em: 14 nov. 2016.

Projeto de Lei do Senado no 193, de 03 de maio de 2016. Inclui entre as diretrizes e bases da educação nacional, de que trata a Lei no 9.394, de 20 de dezembro de 1996, o "Programa Escola sem Partido". Brasília, DF, 03 mai. 2016b. Disponível em: <https://www25.senado.leg.br/web/atividade/ materias/-/materia/125666>. Acesso em: 30 nov. 2016.

Ministério Público Federal. Procuradoria Federal dos Direitos do Cidadão. Nota Técnica $\mathbf{n}^{\mathbf{0}}$ 02/2016 PFDC. 17 ago. 2016c. Disponível em: <http://portal.andes.org.br/imprensa/noticias/impult-723768278.pdf>. Acesso em: 30 nov. 2016.

DE OLHO NOS PLANOS. Maioria dos planos estaduais de educação aprovados incluem referencia à igualdade de gênero. 12 jul. 2016. Disponível em: <http://www.deolhonosplanos.org.br/maioria-dos-planosestaduais-de-educacao-aprovados-incluem-referencia-a-igualdade-de-genero/>. Acesso em 30 nov. 2016.

DESTAQUE que retira perspectivas de gênero das atribuições do Ministério das Mulheres é aprovado. Câmara Notícias. Brasília. 18 fev. 2016. Administração Pública. Disponível em: <http://www2. camara.leg.br/camaranoticias/noticias/ADMINISTRACAO-PUBLICA/503884-DESTAQUE-QUERETIRA-PERSPECTIVAS-DE-GENERO-DAS-ATRIBUICOES-DO-MINISTERIO-DAS-MULHERES-EAPROVADO.html>. Acesso em 29 nov. 2016.

DILMA ROUSSEFF manda suspender kit anti-homofobia. O GLOBO - G1. São Paulo. 25 mai. 2011. Educação. Disponível em: <http://g1.globo.com/educacao/noticia/2011/05/dilma-rousseff-mandasuspender-kit-anti-homofobia-diz-ministro.html>. Acesso em 29 nov. 2016.

FÓRUM BRASILEIRO DE SEGURANÇA PÚBLICA. Anuário Brasileiro de Segurança Pública 2015. São Paulo: Fórum Brasileiro de Segurança Pública, 2015. Disponível em: <http://www.forumseguranca. org.br/storage/download/anuario_2015.retificado_.pdf> Acesso em: 15 nov. 2016). 
MAZZON, J. A. (Coord.). Principais resultados: projeto de estudo sobre ações discriminatórias no âmbito escolar, organizadas de acordo com áreas temáticas, a saber, étnico-racial, gênero, geracional, territorial, necessidades especiais, socioeconômica e orientação sexual. São Paulo: Fundação Instituto de Pesquisas Econômicas, Ministério da Educação, Instituto Nacional de Estudos e Pesquisas Educacionais, 2009.

PARANAGUÁ. Lei no 3468 de 23 de junho de 2015. Dispõe sobre a aprovação do Plano Municipal de Educação de Paranaguá e dá outras providências. Disponível em: <https://leismunicipais.com.br/a/ pr/p/paranagua/lei-ordinaria/2015/347/3468/lei-ordinaria-n-3468-2015-dispoe-sobre-a-aprovacao-doplano-municipal-de-educacao-de-paranagua-e-da-outras-providencias>. Acesso em: 26 set. 2016.

PUGGINA. ORG - Conservadores e Liberais. Proteja seus filhos da ideologia de gênero. Disponível em: http://www.puggina.org/. Acessado em: 12 de out de 2015.

SCALA, J. Ideologia de Gênero: o neototalitarismo e a morte da família. Zenit. 31 jan. 2012. Disponível em: <https://pt.zenit.org/articles/ideologia-de-genero-neototalitarismo-e-a-morte-da-fami-lia/>. Acesso em: 20 set. 2015.

WAISELFISZ, J. J. Mapa da Violência 2012: a Cor dos Homicídios no Brasil. Rio de Janeiro: CEBELA, FLACSO; Brasília: SEPPIR/PR, 2012. Disponível em: <http://www.mapadaviolencia.org.br/pdf2012/ mapa2012_cor.pdf>. Acesso em: 01 out. 2016.

Mapa da Violência 2015: homicídio de mulheres no Brasil.Flacso Brasil. 2015. Disponívelem:<http:// www.mapadaviolencia.org.br/pdf2015/MapaViolencia_2015_mulheres.pdf >. Acesso em: 09 set. 2016. 